\title{
Introduction
}

\author{
Tony Fitzpatrick
}

\section{MAPPING THE AGENDA}

Humans are incredibly adept at solving problems: ingenious, imaginative, resourceful, cooperative. It is not simply about individuals, of course. Over the centuries we have developed political and social systems conducive to problem-solving. In a liberal society the 'separation of powers', designed to respect the sovereign authority of 'the people' and ensure that political control is dispersed and decentralized, allows institutions to make mistakes and to learn from one another. In a democracy the civic culture is one conducive to active citizenship, critical reflection and protest, mutual trust, public debate and an ethos in which people accept responsibility for their lives and social environments confident in the knowledge that they are the ones ultimately in charge of both. In an era when some commentators have begun to envy the strong, technocratic, weight-carrying muscles of China's authoritarian capitalism, the nimble, interlocking fingers of liberal democracy still possess the resources best able to cope with collective problems.

But humans are incredibly stupid at allowing so many problems to develop in the first place and worsen to such a point that the species often seems to flirt unnecessarily with danger, speeding like reckless teenagers to the edge of a cliff in order to throw the brakes at the last second and experience the thrill of a disaster narrowly averted. It is not simply about individuals, of course. Over the centuries we have developed political and social systems conducive to problem-creating. Liberal societies undermine themselves by investing too much power in monodimensional forms of decision-making and authority, including over-powerful states, anti-social markets and social class hierarchies. The separation of powers has been an ideal, but not always the reality, and lacking the openness, transparency and accountability they need, institutions often exhibit a blind determination to keep moving along an established, familiar direction no matter what. And democratic cultures are subverted by vested interests. Politicians and newspapers are able to shape public opinion with frustrating ease; corporations and celebrities are adept at inserting themselves into cultural streams and grafting themselves into the social identities of millions. Mesmerized by the interests of a few, people may be distracted just enough for long enough to ignore the escalation of the dangers they face. 
In short, Winston Churchill's quip about Americans - that they can always be counted on to do the right thing, but only after exhausting all the other options - might apply equally to humanity itself. During the infancy of the species this may not have mattered too much. Arrows and spears have little impact beyond those they injure and kill. But we are now equipped with much more than arrows and spears. From the First and Second World Wars, to the Cuban Missile Crisis, to the financial crashes of 1929 and 2007-08, the last century has been peppered with events that affected the lives of countless millions. And this is not said merely with the wisdom of retrospect. Many people knew in advance that imperialist tensions were mounting, that the post-Great War settlement was a recipe for future instability, that the nuclear arms race and Cold War were dangerous, and that debt bubbles could not keep inflating forever. It is as if, instead of spotting the iceberg at the last minute, the Titanic spent hours merrily steaming towards the damn thing, trusting it to be a mirage that would vanish when the time came.

Why do we so often speed towards the edge? Whenever we played football at school, I - invariably picked to go in goal - was often the amused witness to a common spectacle, where about a dozen children would swarm around the ball instead of spreading themselves across the field to work together. In seeking individual glory, rather than observing the mundane requirements of teamwork, each player was making a minute contribution to a situation that in the aggregate was deeply irrational. In short, this was a collective action problem in which individuals, by pursuing what appears to be a reasonable and rational course of action qua individual, create conditions which undermine the good of everyone. Knowing that disaster is ahead may not, by itself, divert enough people towards alternative courses of action. We so easily become passive bystanders, witnessing a crash in which we are also the willing participants.

And in the century to come? Can we utilize the best of our social and political systems? Can we allow the better angels of our nature to triumph over the drooling idiot that also squats inside there? Can we develop better collective action solutions?

Environmental issues, and climate change in particular, are central to the political, social, economic and moral challenges of the twenty-first century. Outside the saloon bar mentality of those who think that it is all a Eurocratic power grab, everyone knows this. But, as has just been said, knowing and doing are not the same thing. We could have spent the last quarter-century doing much more. The solutions to ecological degradation are actually less drastic than either conservatives (of right and left) fear or radicals hope. But how much easier it has been to still the alarm clock, settle back into the pillow, feign a cough for Mum and get a free day off 
school. Everyone does it. If no one else is willing to make an effort, why should you be any different? You need to conserve your energy, anyway. You've got football tomorrow.

I say 'are less drastic' but this is in truth a moving target. The earlier you spot the asteroid heading your way, the less you have to do to divert it. The longer you delay, the more severe and urgent the action needed to avoid a collision. Those who strive the hardest to preserve the status quo are only ensuring that it cannot be preserved. But before radicals and romantics delight in the prospect of starting civilization all over again on a blank sheet of paper, the delay makes it more likely that those who were deniers and delayers only yesterday will, by tomorrow, be urging crisis management solutions that are highly authoritarian. The newest converts can make the worst zealots.

Yet whatever form it takes, social policies will be central to the conditions which our children and grandchildren will face. This is quite simply because social policies occupy a central position in modern societies. In the United Kingdom (UK), 30 per cent of gross domestic product (GDP), or about two-thirds of government spending, is directed towards welfare services. Some European countries spend more and some spend less. This means that much of what we are asked to vote for during elections concerns social policies. It may well be the case that some on the political right are using post-2008 austerity to dismantle the welfare systems - that, ironically, conservatives initiated back in the late nineteenth and early twentieth centuries - with which they have never been comfortable. But even if Facebook ends up running our hospitals, Amazon ends up running our schools, and arrogant banks, multinational corporations and equity firms end up running our economies (sorry: as if that last one could ever happen!), these will still be social policies, albeit with 'the social' defined largely in terms of profit, profit and more profit.

To date, governmental social policies have done little to register the challenge of climate change beyond the redesign of some buildings and the development of certain emergency procedures; flooding, transport and housing stock retrofitting are areas where agendas are converging to some extent. True, some countries are more advanced than others but I do not think it is yet possible to present a map of 'green welfare systems' in a manner any way equivalent to the kind of cross-national comparisons of social policies that began to appear in the 1960s and 1970s.

The research literatures are gathering pace, though. The Joseph Rowntree Foundation has run a 'Reconciling Environmental and Social Concerns' programme and some interesting work has been done by the New Economics Foundation, among others (including the Economic and Social Research Council and the Natural Environment Research Council). 
In academic circles publications and research projects have been slowly emerging (Huby 1998; Cahill 2001, 2010; Cahill and Fitzpatrick 2002; Fitzpatrick and Cahill 2002; Fitzpatrick 2011a, forthcoming; Aldred 2011; Gough and Meadowcroft 2011). And most social policy textbooks will now offer some mention of the environment and global warming. This is still very much virgin territory, however. The urgency that climate change presents conflicts with the glacial slowness of social research design, fieldwork and dissemination. There is no consensus, in other words, and only a kind of stuttering momentum.

This book is offered as a contribution to that field of scholarship and research, as one more step on the road to some kind of clarity. It does not offer a one-stop shop for those new to the subject. If you do want more of a textbook then you should read Fitzpatrick (2011a). Instead, these chapters attempt to make original but hopefully accessible contributions to the research base. As such, coherence in the themes, concepts and methods of the chapters is less important than their immediacy and relevance to the social and ecological circumstances within which we now find ourselves. These are the topics that some important researchers think are important. A synopsis follows at the end of this chapter.

\section{DEFINING THE PROBLEM}

First of all, let us wrestle with the key terminology. Environmentalism is concerned with the natural environment and so would have a legitimate role to play even if global warming did turn out to be an IslamoEurocratic-Communist conspiracy to prevent the deniers from thinking all of the wonderful thoughts they think. In the nineteenth century Henry David Thoreau and William Morris offered, respectively, right-wing and left-wing takes on society and nature many decades before climate science became mainstream. The climate includes the atmosphere, hydrosphere, land surface, biosphere and cryosphere. Variability is therefore a persistent feature of our climate for the simple reason that all of these spheres interact, driven ultimately by solar activity which is itself variable. There is no such thing as a non-changing climate. However, when we refer to contemporary climate change we are referring more to the rapid global warming created by human activities pouring greenhouse gases (GHGs), particularly carbon dioxide $\left(\mathrm{CO}_{2}\right)$, into the atmosphere and oceans. 'Climate change' and 'global warming' mean more or less the same thing, then. When relevant, this book also refers to broader environmental issues of resource depletion and management.

Unfortunately, most of the fifth report of the Intergovernmental Panel 
on Climate Change (IPCC) is not due to be published until after this book has gone to press, but the basics have been clear for many years now. In pre-industrial times there were 280 parts of $\mathrm{CO}_{2}$ for every million molecules of dry air. By 2013 this had risen to 400 parts per million. Compared to pre-industrial times, it means we have already experienced an average rise in global temperatures of at least $0.8^{\circ} \mathrm{C}$, with another $0.6^{\circ} \mathrm{C}$ almost certain to happen whatever we do and an additional $0.6^{\circ} \mathrm{C}$ after that also very likely. This may not sound like much, especially to Britons who can experience widely varying temperatures on a typical day. But in terms of climate these temperatures matter significantly: $2^{\circ} \mathrm{C}$ of warming is widely regarded as the upper limit beyond which global warming becomes dangerously unmanageable.

According to the IPCC (2007: 48) the health status of millions of people, especially in developing countries, is going to be affected through increases in malnutrition, diarrhoeal and infectious diseases, and cardio-respiratory diseases due to higher concentrations of ground-level ozone in cities. Furthermore, the warming we have already experienced has led to increasing and disastrous incidents of hurricanes, floods, wildfires, droughts, deforestation, species extinction and heatwaves, all of which particularly affect the poorest. At $1.5-2^{\circ} \mathrm{C}$ of warming these will certainly be joined by severely rising sea levels, irreversible ice sheet loss, mass species extinctions, larger and more frequent droughts and famines, rainforest collapse, coral reef devastation, acidic oceans and mass ecological migration as levels of potable water and crop yields decline.

Weighty stuff. So where, secondly, might social policy come into the picture (see Fitzpatrick 2011b: Ch. 3)? In addition to what has been said above - about the centrality of social policies to modern societies - both environmentalism and social policy are concerned with well-being. The latter has been receptive to the idea that well-being cannot be measured in terms of or ensured by rising standards of living. Beyond a certain point, 'quality of life' matters more. One hope is that this realization will inspire a social politics different to the economic liberalism of the last 35 years and offer either a new kind of capitalism or even post-capitalist possibilities. Environmentalists from Thoreau and Morris onwards have long championed this kind of ethos, associating well-being with 'being well with and for the natural world'.

Furthermore, one of the roles played by social policies over the last 100 years has been to offer collective security against collective risks and uncertainties. Jim and Jan know there is a 25 per cent chance of an individual becoming seriously ill. They could insure themselves separately and individually, but in a private system where the priority of firms is to make a profit, a large part of the risk is passed to individual policyholders (in 
the form of higher premiums and restricted conditions for making claims) and if they attract insurance at all high-risk individuals may only receive coverage which is inadequate and/or highly expensive. But pooling their premiums (or contributions) in a social insurance scheme coverage can be universal, relatively cheap (with the state as guarantor) and inclusive. Thus Jim and Jan both gain, even if neither of them becomes ill, because they have a firmer base of security from which to plan their futures. Whether and to what extent a similar scheme of mutual security can be extended to climate change is yet to be seen.

Yet if there are potential synergies between environmentalism and social policy there are also various hurdles. Modern welfare institutions developed under and according to the expectation that economic growth would continue indefinitely. Developed as a settlement within the capitalist drive for affluence, the welfare state sought legitimacy in its capacity to promote growth and provide some stability to the boom-and-crash hysterics of free markets. The same businessman who complains about taxes and bureaucracy would complain even more if their consumers died through lack of spending power during economic downturns. But the labour movement saw an opportunity here also: to moderate and even socialize capitalism against a background of always rising affluence. It is easier to make a case for progressive public spending when annual GDP and productivity growth is high enough to ensure that the private sector does not lose out. When growth faltered in the 1970s the tensions between public and private were exposed to an extent that has never faded - albeit in some countries (like Britain) more than others (such as Germany).

If, due to climate change, our measurement and entire conception of growth, development and progress need to change, then what are the implications for social policy? There are several versions of a 'low-carbon economy', of course, but only the most 'greenwashed' of them advance a business-as-usual agenda. Can welfare systems adapt to, or indeed even shape, new realities? Can those dedicated to distributive justice learn to be less reliant on calculating which portion of GDP growth can be redistributed? How can we raise carbon taxes without the regressive effects of such taxes hitting low-income households the hardest (the very people who tend to emit the least amount of carbon in the first place)? How, then, can we anticipate and insure ourselves against climate-related uncertainties? We need long-term resilient and adaptive systems, to be sure. Yet what does that mean?

These are difficult questions and only the dogmatic insist that the answers to them are nonetheless easy. What seems clear is that ecosocial policies will be as different to the social policies of today as those are to the social policies of the nineteenth century. This claim may turn out to be 
wrong. Perhaps today's combination of deregulated markets, governance by and through corporations and financial institutions, widening social inequalities, the privatization of public goods and shrinking state support is about to deliver the utopia its neoliberal advocates imagine it has spent the last four decades already delivering. But if not, then not only will we continue to require welfare systems that restrict, regulate and reshape market forces, but we will need environmental systems that merge with and enhance the social agenda. Thus, while they must evolve from the past, measures suited to the decades ahead cannot simply replicate the social protections of the past. The seeds of the future are scattered everywhere around us and although we must identify and nurture the most important and with some urgency too - the garden is so vast across time and space that the maps of the gardener are always simplistic by comparison. Few visionaries in the 1880 s could have anticipated a world dominated 70 years later by jets and cars, television and movies, artificial satellites and nuclear power, Cold War superpowers and nuclear weapons.

Major challenges lie ahead, in other words. If we are to meet those challenges, we need to develop conceptual frameworks and research priorities that dovetail with developments in other disciplines. This means updating ourselves on the state of existing research and relevant debates. To this end, The International Handbook on Social Policy and the Environment brings together two dozen experts across a range of subjects to present summaries of their recent research, their views of recent policy developments and notions of what ought to happen next. Some of the chapters are theoretical and some are empirical but many allow one to inform the other. The chapters do not speak to the same agenda, nor do the contributors agree with one another about everything, but some fascinating themes and synergies are present nonetheless.

\section{SYNOPSIS}

\section{Part I: Justice and Poverty}

In Chapter 1 André Schaffrin offers a comprehensive overview of the relationship between climate change and social policy, looking at the potential conflicts between them and the opportunities which exist to align welfare and climate mitigation goals. He analyses the costs of mitigation and discusses the concept of green growth as a potential way to integrate the principles of economic growth, environmental preservation and social equality. It is in this context that he focuses upon two debates: 'green jobs' and energy inequalities in the housing sector. Schaffrin then discusses major 
differences in the ways various welfare regimes relate to issues of environmental justice and green growth. Overall, he finds that much depends on the specific design of climate mitigation instruments and on how these are integrated into social policy systems and economic structures. For instance, social democratic and (to some extent) conservative nations are those most capable of achieving green growth due to their support for skills and technical innovation, and their combination of flexibility and security. Furthermore, whether climate policies create social injustices and problems is likely to depend upon both pre-existing levels of inequality and the welfare state's capability to accommodate the necessary changes. Schaffrin therefore anticipates and critiques many of the questions and debates with which we engage throughout the rest of this book.

Milena Büchs, Nicholas Bardsley and Sylke Schnepf examine climate change mitigation in terms of distribution and fairness in Chapter 2. Which groups bear the highest burdens - or receive the greatest assistance from mitigation policies and how does this relate to their contribution to emissions? It is already well established that general carbon taxes are likely to have regressive impacts, placing higher relative burdens on poorer than on richer households; and it is often argued that these effects can be reversed, through rebate schemes or equal per capita carbon allowances, for instance. But does this hold for all types of emissions, for example domestic energy and transport? And what role do household characteristics other than income and household size play in the distribution of benefits and burdens? Büchs, Bardsley and Schnepf provide an overview of mitigation policies and examine potential distributional implications across different emission domains. Their analysis is based on a dataset of household $\mathrm{CO}_{2}$ emissions derived from UK expenditure data. It shows that mitigation policies that only target home energy emissions are least equitable from a distributional point of view, not only in terms of differences among income groups but also in relation to other household characteristics.

In Chapter 3, Tony Fitzpatrick offers a conceptual approach to similar questions of fairness, distribution and poverty, before reviewing a range of empirical evidence drawn mainly from the UK. What implications may climate change have for UK rates of poverty? To what extent might poverty constitute a hindrance to climate adaptation and mitigation efforts? The chapter critiques the capabilities approach and favours one more firmly grounded in a notion of resources. Since exclusion from resources is often what drives spatial and temporal forms of poverty, it can be expected that without clear principles of justice to ensure the fair distribution of and access to 'socionatural resources' (energy, food, land, air, water), emerging types of 'ecosocial poverty' will worsen in the coming decades. The chapter then reviews data from three areas - housing, transport and air pollution - 
in order to substantiate this claim. It concludes by offering an ecosocial definition and theorization of poverty as it is increasingly manifesting itself in this era of rapid climate change.

\section{Part II: International Developments}

Much of the rest of the book looks beyond UK data, beginning with Chapter 4. Erik Gawel and Wolfgang Bretschneider follow through on the above notion of resources being both social and natural by analysing water and energy services in Germany, a country generally thought to exemplify a conservative approach to social policies. They consider two questions. What does affordability mean? What role do affordability problems play in Germany's water and energy sectors? They examine the strengths and weakness of what is called the conventional affordability ratio (CAR), a widely used measure of affordability. They offer a model that basically distinguishes between ability to pay and willingness to pay, and which highlights the shortcomings of the CAR and those of its alternatives, the potential affordability approach and the residual income approach. There is no ideal way of measuring affordability, they conclude. The chapter ends by considering the main social policy alternatives to rising energy and water prices, given the need to conserve natural resources while protecting the most vulnerable. These include: income transfers (to help households cope with rising prices), social tariffs (reducing utility charges for certain groups), increased household efficiencies (in appliances such as 'white goods') and better information (perhaps assisted through the installation of smart technologies). Gawel and Bretschneider's preference is for solutions which do not adversely affect the market allocation of scarce resources through price distortions.

Because social democrats have long envied the Scandinavian welfare states, and since those countries are often portrayed as 'environmental pioneers', what lessons can be learned from their attempts to integrate social policy and environmental policy? In Chapter 5, Anders Branth Pedersen and Helle Ørsted Nielsen review the evidence which, in many cases, is surprisingly rare. They explore the implications of green taxes for levels of inequality in Scandinavia and propose that no conclusive picture emerges due to the complex relationships between prices, revenue recycling, tax reforms and environmental improvements. However, they do offer some general conclusions. For instance, some green taxes (on water and electricity) are more regressive than others (on cars); rural households are more adversely affected than urban ones; and measures to reduce air pollution will typically benefit the poorest the most. Crucially, Pedersen and Nielsen highlight the extent to which politics and governance matter. 
Through careful design of the tax system the most vulnerable groups can be protected and may even benefit. Green taxes are therefore neither automatically regressive nor progressive; what matters is the egalitarian intent (or otherwise) of the tax reformers and policymakers.

Michael Briguglio, Maria Brown and Ian Bugeja investigate, in Chapter 6, the extent to which European environmental non-governmental organizations (ENGOs) have or have not been institutionalized by political and policymaking systems, the reasons for this and whether such cooption has been a reasonable price to pay. They find that ENGOs are often characterized by an ideologically moderate form of environmental politics. This may or may not lend them influence within government institutions and other relevant agencies, though the effect is to sever them from the more radical and idealistic aspects of the ecological movement. This might deprive them - and the rest of us - of the 'holistic', root-and-branch thinking which we need. In particular, the need to rethink the social and economic contexts of social policy and the nature of capitalism itself.

Moving beyond Europe, Judith Cherni explores the impact of the Washington Consensus on Latin America in Chapter 7. Market deregulation and liberalization have significantly affected agricultural practices, with consequences for both the quality of life and ecological well-being. For instance, in order to make a country attractive to inward investment, environmental controls and regulations have been loosened and demoted down the list of priorities. Social conditions in Latin America have been similarly ignored in the rush for export-driven profits and it is no surprise that local people and local economies have suffered accordingly, often characterized by increased poverty. Genetically modified (GM) monoculture has been a particular villain here. The fertility and sustainability of the land is sacrificed in order to speed up the pace of production; and farmers become dependent on corporations producing GM organisms, such as Monsanto. The results include a loss of biodiversity and natural habitats, soil erosion, desertification and water contamination; multinationals become dominant, food production is compromised and local communities are displaced. Ill health is another consequence, therefore, and so Cherni spends some time on a case study of Ituzaingó in Argentina. Yet before we stereotype the people affected merely as passive victims, Cherni also presents evidence about the concerted acts of resistance which inhabitants have initiated in order to try and regain control of their lives and communities.

In Chapter 8, Yasuko Kameyama offers a concise overview of environmental policies and social policies in post-Second World War Japan, highlighting the considerable extent to which these have not been subject to integration or cross-fertilization. Economic prosperity was prioritized 
in the post-war era (which Kameyama calls the 'expansion stage'), partly in order to fund social welfare programmes, which caused ecological problems such as pollution. During those decades very little emphasis was given to environmental values per se, and there was barely any such thing as a 'green movement'. In the later 'contraction stage' - from the late 1980s onwards - the Japanese economy and welfare system had to adapt to a period of sluggish growth, one not conducive to systematic consideration of environmental issues. However, the increasing prominence given to women, young people - facing a less certain future than their parents had - and NGOs, non-profit organizations and various citizens groups has arguably altered social and ethical norms at a grassroots level in ways that may portend change. It is the new stage - following the earthquake and tsunami of 2011, and the subsequent national soul-searching about nuclear power - which may herald a consequent shift in social values. With nuclear energy becoming less popular, many are advocating alternative forms of energy production, including renewables. Debates about this for the future direction of social policy are in the early phases but this is one in which civil society organizations and citizens' associations are taking a lead. Kameyama therefore ponders whether Japan is entering into a new 'sustainability stage'.

In Chapter 9, Karen Bell challenges what she sees as the continued economic consensus, before defending the thesis of the 'degrowth' movement against its main criticisms. If this argument holds, then a central pillar of and justification for capitalism begins to topple, she argues. Although 'green growth' is better than unsustainable growth we need to value the social and ecological imperatives that capitalism largely ignores. Growth is all too often presented as a solution to the very problems created by growth. Since a proper understanding of well-being associates it with the fulfilment of basic needs, we ought to reimagine our social and environmental priorities. But what would this imply? Are there any practical examples upon which we can draw? Bell draws upon recent data to suggest that Cuba has achieved a high level of social and ecological well-being. She attributes its success to (among other policies):

- decentralized energy systems;

- free universal provision of healthcare, education and social services;

- free use of community facilities;

- localized production and consumption;

- low-cost public transport;

- minimal packaging and advertising;

- rent caps;

- restricted car ownership. 
Bell considers the extent to which these policies are consistent with capitalism. Though some capitalist systems are preferable to others, she argues that only a socialist alternative to the commodifying, competitive and profit-obsessed characteristics of capitalism will suffice.

In Chapter 10, Julie MacArthur explores the social economy in Canada and the extent to which this can and does provide an alternative to the neoliberal orthodoxies of Canadian governance. Inspired and driven by a different set of principles, processes and objectives, the diverse organizations that make up the social economy have long been championed by those seeking to break the dominance of both states and markets over civic life. To what extent, though, can they facilitate ecological sustainability? She argues that while the social economy may serve the goals of sustainability, some aspects of it also serve the anti-state 'gap-filling' requirements of neoliberalism. Only a political and transformationalist approach, therefore, will allow the potential of the social economy to be realized. This agenda is required, given how far Canada currently is from realizing the kind of social and environmental values which we urgently need. MacArthur then maps the scope and scale of, and diversities within, the Canadian social economy, focusing on three sectors - forestry, food production and energy - and relating these to issues of profit, people and power. She concludes that while the social economy has a great deal of potential - and some actual achievements - only coordination and systematic changes to the public policy regime is likely to effect real change. A 'revolution by stealth' is unlikely.

Finally, in Chapter 11, Karen Hussey draws on Australian data to investigate the extent to which the use of market mechanisms within environmental policy conflicts with both long-term social justice issues relating to human rights and shorter-term equity issues regarding the allocation and use of natural resources. Using Australia's national water policy reforms as a case study, she explores the opportunities, limitations and possible consequences of a shift towards market-based instruments. The implications of water markets and pricing for rural and urban communities, and the extent to which Indigenous interests have been accommodated in Australia's flagship water policy, are given particular attention. Hussey concludes that, though they bring actual and potential benefits, market mechanisms raise important issues concerning equity, fairness and justice.

\section{Part III: Making and Implementing}

The book then focuses upon various themes relevant to the business of making and implementing policy and social reforms. For instance, earlier chapters have underpinned the importance to social policy of new issues, 
such as energy policy and the energy efficiency of buildings and residences. But who should have the authority to make decisions about these and other domains? Should decision-making power be centralized or devolved? What role has the European Union (EU) played in developments to date? How much policy integration is in evidence? Elin Lerum Boasson and Jørgen Wettestad offer an analysis of EU policymaking in Chapter 12, looking at the underlying mechanisms and the extent to which a 'policy coherence' has or has not emerged. They explore four developments: the emissions trading system, energy renewables, carbon capture and storage, and energy efficiency in buildings - in terms of different types of integration:

- Functional interaction, when policymakers emphasize actual or potential intersections between policies.

- Bargained interaction, or the strategic links that actors establish in order to steer policy development in desired directions.

- Institutional interaction, where the character of historically dominant policies influences the approach that policymakers take in new areas.

- Persuasion interaction, when actors with a high status in one area introduce that policy's characteristics into another policy area.

Boasson and Wettestad reach the conclusion that the level of interaction and integration is actually quite threadbare, despite EU rhetoric which often points in the opposite direction. There are some examples of good strategic focus and policy coherence, but fewer than we have been led to expect.

There are considerable difficulties in combining the social and ecological agendas at a global and transnational level too. The language of cross-national and multi-sectoral partnership is commonly heard and certainly easy to invoke, but in practice there are numerous organizational and procedural obstacles which have to be surmounted, many of which derive from familiar problems within policymaking and implementation of power imbalances, economic resources and political conflicts. Magnus Boström illustrates this with reference to multi-stakeholder organizations in Chapter 13. He outlines the meaning of the multi-stakeholder approach and critiques its potential for reconciling social and environmental interests. He observes that there are three principal challenges with which the various agencies and actors must grapple if that potential - and thus social and environmental justice - is to be realized. The first concerns the cultural and 'cognitive' separation between the social and the environmental. The second looks at pre-existing power asymmetries among the participating stakeholders. Finally, he discusses participatory challenges which arise 
when taking globally spatial and temporal dimensions into account. Boström concludes his chapter by considering the crucial role that capacity building and empowerment must play if the goals of social and environmental sustainability are to be more fully and effectively embedded within multi-stakeholder relations and practices.

In Chapter 14, Carolyn Snell and Sarah Brooks-Wilson trace one 'big idea' - sustainable development - into the interstices of education policy and reform, investigating how and why the term is taken up across differing nations, governments and establishments. Focusing upon England and Wales they provide a case study of the effects of educational projects and some of the barriers faced by schools and teachers. They found that despite (or perhaps because of) its holistic, wide-ranging remit, sustainable development is not integrated into all aspects of the learning experience. It also competes for time and attention in an educational environment buffeted by as many political and financial pressures as pedagogic ones. In short, innovation and leadership at a local level cannot substitute for coordination across the sector; coordination that may be inimical to the neoliberal preference for market-oriented, laissez-faire choice. Snell and BrooksWilson thus illustrate successfully the opportunities and constraints facing those seeking to translate abstract concepts into practical, down-to-earth projects that not only educate but will hopefully inspire young people to make the changes that they, and we, need sooner rather than later.

\section{Part IV: Alternative Visions}

The final chapters are more theoretical in their attempts to understand what is at stake in the agenda presented to us by the ecological challenges of the twenty-first century. To what extent must social policy researchers and commentators revisit the fundamental concepts upon which their discipline rests? To what extent have we lost sight of first principles, and how do those principles enable us to respond to and shape the social, economic and ecological dilemmas that loom before us?

Hartley Dean clarifies the basis upon which humans may claim social rights to natural resources in Chapter 15. In thinking about the relation between humanity and nature, he starts by contrasting an anthropocentric, Genesis conception in distinction to an ecocentric, Gaia conception. There follows a series of taxonomies which, layered on top of one another, are designed to subvert that distinction and draw out some fundamental repertoires - the political and moral 'logics' - which underpin debate about the natural world, humanity's role within it and the significance of social policy in mediating their interaction. Dean finds value in elucidating Marx's concept of Stoffvechsel which captures the symbiotic, 
metabolic interrelationship of the social and the ecological. The well-being of each is the condition for the well-being of the other, an 'equilibrium' that capitalism undermines by separating and setting them against one another. Healing this rift therefore requires a mode of production that is not based upon market exchange, exploitation, profits and commodification. At its best, social policy looks through the capitalist looking-glass to post-capitalist forms of association, but only through the substantive decommodification of labour, land and human services can the radical and critical energies of social policies be renewed. Climate change provides the stage upon which battles are being revived between those who make capitalist markets the alpha and omega of our social and natural worlds and those who seek new ways of thinking about and organizing social rights.

Hovering above debates about social policy and environmental policy are some very large ontological and ethical questions. In Chapter 16, Tony Fitzpatrick contrasts two philosophies which attempt to understand what we mean by 'nature'. If we claim that humans are woven into and interdependent with the rest of nature, then presumably we should try to understand what we mean by 'nature'. One philosophy is thoroughly teleological, exemplified by Aristotelianism. The other is non-teleological and is exemplified by Epicureanism. The chapter offers a close reading of Aristotle's teleological reasoning as articulated in his physical, metaphysical, biological and ethical accounts. It proposes that distinguishing between those aspects (the physical and metaphysical) which, at best, have been made redundant by modern science or, at worst, were always problematic, and those which still attract support (the ethical, in particular) is less easy than Aristotelians imagine. A teleological approach underestimates the role played in human affairs by luck and contingency; it relies upon a strict anthropocentric distinction between humans and non-humans; and it encourages an attitude of fate, submission and deference. The chapter concludes by contemplating whether Epicureanism could provide a more convincing foundation for social and environmental philosophy and ethics.

\section{REFERENCES}

Aldred, R. (2011) 'Social justice, social policy, and the environment', special issue of Critical Social Policy, 31(2): 171-324.

Cahill, M. (2001) Social Policy and the Environment, London: Routledge.

Cahill, M. (2010) Transport, Environment and Society, Maidenhead: Open University Press.

Cahill, M. and Fitzpatrick, T. (2002) Environmental Issues and Social Welfare, Oxford: Blackwell.

Fitzpatrick, T. (ed.) (2011a) Understanding the Environment and Social Policy, Bristol: Policy Press. 
xxiv International handbook on social policy and the environment

Fitzpatrick, T. (2011b) 'The challenge for social policy', in Fitzpatrick, T. (ed.), Understanding the Environment and Social Policy, Bristol: Policy Press.

Fitzpatrick, T. (forthcoming) Climate Change and Poverty, Bristol: Policy Press.

Fitzpatrick, T. and Cahill, M. (2002) Environment and Welfare, Basingstoke: Palgrave.

Gough, I. and Meadowcroft, J. (2011) 'Decarbonising the Welfare State', in Dryzek, J.,

Norgaard, R. and Schlosberg, D. (eds), Oxford Handbook of Climate Change and Society, Oxford: Oxford University Press.

Huby, M. (1998) Social Policy and the Environment, Milton Keynes: Open University Press. IPCC (2007) Climate Change 2007: Synthesis Report, Geneva: IPCC. 